\title{
Reflective journals in service learning: a window into assessing learning and change in students' attitudes
}

\author{
RWE Joubert and AT Hargreaves*
}

\begin{abstract}
As part of the curriculum for Community Based Rehabilitation, final year students from the School of Audiology, Occupational Therapy and Speech-Language Pathology are involved in service learning projects in a semi rural area in KwaZulu-Natal. The project runs one day a week from February to October and at the end of each day students submit a journal in which they reflect on each days activities and their learning experiences. The researchers used these journals as a source of data for determining learning and attitude change in students over the entire period of the practical. Method: 12 journals were randomly selected from over a period of 5 years and including students from all three disciplines. Content analysis was done to determine changing learning and attitudinal patterns over the 7 month period of the practical. The results revealed a rich pattern of emotional experiences coupled with positive attitudinal change and suggest a valuable source of evaluating learning progress in students.
\end{abstract}

Keywords: Service learning, reflective journals, community based rehabilitation.

Disciplines: Occupational Therapy, Education, Philosophy, Hermeneutics.

\section{Setting the tone, context and background for the study}

In the fourth and final year of the bachelor degrees of audiology, occupational therapy and speechlanguage pathology at the University of KwaZulu-Natal, students take a service learning module aimed at equipping them with the necessary knowledge, skills and appropriate attitude to practice within diverse cultural and community contexts. The site selected for placement is a semi rural area in the well known Valley of a Thousand Hills. The students participate in four different projects two of which are aimed at providing rehabilitation and support for the community health workers (CHWs), mothers and caregivers of severely disabled children.

The area is approximately 35 kilometres from the city of Durban and students work there one full morning a week from March through to October. One of the main goals of the fieldwork is to ensure sustainability

* Department of Occupational Therapy, University of KwaZulu-Natal, Private Bag X54001, Durban, 4000. 
when the students leave. So there is a lot of emphasis on empowering the caregivers and CHWs to take over the project when the students move out for the period between October and February. People living in the area experience relatively high levels of poverty and unemployment.

Geographically the area consists of a large basin containing many smaller hills and valleys, it is fairly densely populated and reasonably accessible through a main tarred road and access to homesteads is by dirt roads. Housing varies from wattle and daub square and rondavels to some fairly sophisticated brick and tile homes. There are a scattering of community halls, schools, clinics, spaza shops and taverns and transport is mostly by minibus taxi although some have their own vehicles.

\title{
The value of service learning and reflection
}

Service learning can be defined as:

\begin{abstract}
a method under which students learn and develop through thoughtfully organised service that is conducted in, and meets the needs of, the community and is coordinated with an institution of higher learning and with the community, helps foster civic responsibility, is integrated into and enhances the academic curriculum of the students enrolled and includes structured time for the students (and community) to reflect on the service experience and outcomes. (Duncan \& Aulsop (2006) Adapted from the American Association of Higher Learning, 1999)
\end{abstract}

Service learning and its value cannot be under estimated in the training of rehabilitation professionals as a means of providing a learning context that allows students to engage at a realistic level with the communities that they serve and experience directly their needs, values, problems and realities. Previously health care education was confined to the sterile and unrealistic confines of clinics, hospitals and institutions where students had little if any exposure to these realities and thus qualified with a distorted perception of the real life challenges facing the many disabled people they served. In professions such as those dealing with communication and occupational disorders, the need to have an intimate understanding of the cultural, socio-economic and geographical diversity in South Africa is an essential ingredient to being able to provide sensitive and realistic interventions to overcome these problems.

The theoretical framework for this particular project is that of social justice. The particular population in which the service learning takes place is an historically disadvantaged community which has had very little access to rehabilitation. As can be seen in the learning outcomes part of the students brief is to be aware of national policy and legislation and ensure that it is being properly implemented at grass roots level. Braveman \& Bass-Haugen (2008) maintain that social justice and health disparities play an integral role in the development of theory and interventions as they relate to therapists working within communities, populations, and society at large.

Apart from gaining realistic knowledge about the communication and occupational problems that face all South Africans and learning appropriate skills and strategies for dealing with them, working in a service learning context also allows for the development of attitudinal and spiritual components of the professional "self" that are not easy to come by in the clinical hospital or institutional settings. 
The outcomes of the particular service learning module under discussion are that on completion of the module the student should be able to:

- Demonstrate sensitivity to diversity and appropriate attitude and ability to work in different community and cultural settings;

- Assess and analyse a community using correct assessment and screening methods;

- Plan and implement appropriate interventions and recommendations for different settings;

- Demonstrate a sound knowledge, integration, application and understanding of Primary health Care and CBR principles and issues related to the District Health System;

- Be familiar with the current trends in national policy that have direct or indirect impact on a particular community and the country as a whole;

- Demonstrate an ability to deal with community structures and show appropriate attitude, process and procedure for community entry and negotiation;

- Demonstrate the ability to use appropriate referral systems;

- Demonstrate a thorough understanding of the needs of care providers, effectively consult and transfer of skills to both family members and employers;

- Advocate for the rights and needs of the communities within which they work; and

- Demonstrate a sound understanding and application of professional ethical principles as these would apply in community settings.

Integral to the concept of service learning is the ability of the student to be reflective in his/her practice. Duncan \& Watson (2004), describe the purpose of reflective practice as a means of revisiting occurrences of the past in order to gain a deeper understanding of them through recall. They maintain that the process of reliving these past experiences may often evoke new dimensions of understanding that were not evident at the time. Johnson et al (1991) suggest that if learners are to function better tomorrow than they did the previous day then they need to reflect on how their actions could be more effective and plan how to do this in the next session.

Students registered for this module are required to keep a reflective journal of each day's learning experiences. It is handed in to their fieldwork coordinator at the end of each day for reading and comment and contributes towards the formative assessment of each student.

Reflection in education is used as a method to develop student's self awareness through an inner dialogue. The purpose of the end product is not directed so much at a resolution as it is at a better understanding of the problem (Pavlovich, 2007). In this particular instance the use of reflective journals was directed specifically at improving the students insight into his/her Service Learning experiences and to develop a greater need for taking accountability for reflecting on these experiences so that they would enhance the students learning process. Because of what Pavlovich (2007) refers to as the students investment of both their self image and personality into their journals, the subjective element becomes extremely difficult to mark in terms of giving the students annual year mark or percentage for each journal. In this particular instance and for these reasons, students are not marked on the personal content of their reflections but 
rather for work habits such as handing in on time and an indication of time and effort taken to complete reflections for example a half page reflection for a whole mornings involvement versus 4 pages of reflections for the same time. Thus they have a reasonable sense of freedom to express themselves openly and honestly without feeling they have to say what their tutor wants to hear.

\section{Literature review.}

Higher education institutions in the African countries are striving towards ensuring that their curricula enable students to develop specific competencies that are transferable to a variety of contexts (Nygaard, Hojlt \& Hermansen, 2008). Service learning facilitates this shift towards learning that embraces the natural context. During their service learning practical, students have to integrate knowledge learnt from their community module and other modules (i.e. physical, psychosocial and paediatrics) within the community context in which they are placed.

According to Bringle \& Hatcher (2005), service learning enables students to integrate community activities with educational objectives. The students are required to practically implement theoretical knowledge. This then allows them to attach practical meaning or redefine this knowledge if necessary based on their experiences in the community. One of the outcomes for this particular module as mentioned previously relates to advocating for the needs and rights of the community. Engagement with the community provides students with the opportunity to practically employ strategies that will lead to achievement of this outcome. Students also gain increased appreciation of their discipline as they begin to see the significance of their role in the community (Julie, Daniels \& Adonis, 2005).

In addition service learning is a mutually benefiting teaching strategy. The benefits of service learning are enjoyed by both the provider and receiver of service (Mitchell \& Humphries, 2007). The community provides resources in terms of people and experiences of strengths and needs while the students bring academic knowledge and training that the community requires.

Bringle \& Hatcher maintain that reflection is an integral element of service learning. They defined reflection as

... consideration of an experience based on particular learning objectives (2005: 27).

Students have to reflect on their experiences at their community site through journal entries. This requires of them to think about their experiences in a systematic way that allows them to relate their experiences to the theory taught. When writing a reflective journal students have an opportunity to think about their experiences and attach meaning to them (Hubbs \& Brand, 2005). Students are meant to step back and reflect on the experience and not merely regurgitated on the content of the activities done.

Reflective journaling leads to increased self awareness and leads to development of critical cognitive strategies like reflective skills, critical thinking and integration of theory and practice (Hutchings, 2006). It therefore allows the facilitator, who then reads the journals, to assess whether or not the students 
have adequately integrated their knowledge and thus offer appropriate feedback. Hutchings (2006) also emphasised that guidance is imperative in reflective writing. The facilitator reads the journal and provides feedback to the student which is essential in reinforcing development of reflective skills.

On the contrary, Hubbs \& Brand (2005) caution that reflective journaling can have negative outcomes in cases where students reflect at a superficial level and fail to reach higher levels of critical thinking at the end of the module. Hutchings (2006) also stated that students take a risk by sharing their thoughts and feelings with a facilitator who is responsible for their evaluation. Students might therefore, suppress their true feelings and may write what they know will please the facilitator. For example, students might suppress their feelings about certain cultural practices that might be in conflict to their beliefs, because they are ware that they are expected to display cultural sensitivity.

\section{Methodology}

A random selection of twelve reflective journals from all three disciplines was collected over the period from 2002 to 2006 from students who had all attended the Sthandokuhle ${ }^{1}$ support group. Informed verbal consent was obtained from these students on the condition of anonymity and respect for their confidentiality in terms of storage of these journals and disposing of them after data analysis. A breakdown of the students, their race and the disciplines they came from can be seen in Table 1 .

Table 1: Summary of Reflective Journals and their authors which were analysed for this research

\begin{tabular}{|c|c|l|l|}
\hline Journal \& Student code & Year of study & Discipline & Race \\
\hline A & 2003 & Audiology & African \\
\hline B & 2003 & Audiology & Indian \\
\hline C & 2003 & Occupational therapy & White \\
\hline D & 2004 & Speech-Language Pathology & White \\
\hline E & 2005 & Occupational Therapy & Indian \\
\hline F & 2005 & Occupational Therapy & White \\
\hline G & 2005 & Occupational Therapy & African \\
\hline H & 2005 & Audiology & African \\
\hline I & 2005 & Speech-Language Pathology & White \\
\hline J & 2006 & Occupational Therapy & African \\
\hline K & 2006 & Occupational Therapy & African \\
\hline L & 2006 & Occupational Therapy & African \\
\hline
\end{tabular}

1. Sthandokuhle, which means "we rejoice in goodness" was the Zulu name of the site where the students met with the community health workers, caregivers and their disabled children. 


\section{Data analysis}

This was guided by two focus areas which were:

- To establish the specific themes that arose from the students reflections which indicated what student's had learnt during the service learning practical as related to the learning outcomes; and

- To establish if the student's reflections revealed whether they had achieved attitudinal changes inherent in some of the learning outcomes for the module.

Using hermeneutics the researchers took into account the interactive nature of the research and the lived experiences of the students as reflected in their journals . A document analysis of the student's reflective journals was undertaken and the researchers worked inductively towards articulating the research focus described above.

Analysis for the first focus area were as follows: The journals were equally distributed between the two researchers with the directive to read through them and make notes on common themes and patterns that emerged, particularly with regard to learning experiences. On reconvening, the researchers then compared their themes to establish if there was consensus and/or similarities between them. The initial comparison can be seen in Table 2 .

Table 2. Comparison of both researchers initial independent analysis of emerging themes

\begin{tabular}{|c|c|c|}
\hline THEME & RESEARCHER 1 & RESEARCHER 2 \\
\hline $\begin{array}{l}\text { 1. Changing feelings and emotional } \\
\text { responses }\end{array}$ & $\begin{array}{l}\text { Emotional experiences i.e. } \\
\text { - } \quad \text { Naîve feelings about impressions } \\
\text { - } \quad \text { Disappointment and thwarted ex- } \\
\text { - } \quad \text { Othectations } \\
\text { - }\end{array}$ & $\begin{array}{l}\text { - Positive Emotional learning } \\
\text { - Negative emotions e.g. expectations, } \\
\text { barriers }\end{array}$ \\
\hline 2. Learning experiences & $\begin{array}{ll}\text { - } & \text { New Learning } \\
\text { - } & \text { Exposure to new situations } \\
\text { - } & \text { Through team sharing }\end{array}$ & - Promotion of group participation \\
\hline $\begin{array}{l}\text { 3. Evolution of a strategies to deal } \\
\text { with emerging needs and problems } \\
\text { experienced on all levels }\end{array}$ & $\begin{array}{l}\text { - Emerging ideas and use of initiative } \\
\text { e.g. flexibility/adaptability; exploring } \\
\text { solutions }\end{array}$ & $\begin{array}{l}\text { - Problem solving e.g. dealing with unex- } \\
\text { pected incidences. }\end{array}$ \\
\hline $\begin{array}{l}\text { 4. Awareness of their role in making a } \\
\text { difference }\end{array}$ & $\begin{array}{l}\text { - Observing outcomes and change } \\
\text { as a result of their actions }\end{array}$ & $\begin{array}{l}\text { - Positive moving towards group partici- } \\
\text { pation } \\
\text { - Beginnings of evidence of shift of con- } \\
\text { trol project from students towards group } \\
\text { members }\end{array}$ \\
\hline
\end{tabular}




\section{Discussion of findings}

\section{Theme 1: Emotional lability}

There were four basic sub categories of emotions displayed in the reflective journals. While these four sets of emotions were revealed by the students intermittently throughout the length of the practical exposure, they tended to follow a pattern of dominance of one over the others in more or less the following order:

- Mixed emotions;

- Positive emotions;

- Negative emotions; and

- Emotions related to self esteem and confidence.

Initially, in the early days of exposure to the Service Learning environment, students displayed mixed emotions of apprehension, anticipation and anxiety that were fairly rapidly replaced with those of excitement and confidence. This also occurred in the first few weeks, as some discovered that what they had anticipated as fear of a strange and possibly hostile environment had revealed a much more hospitable one. This was then replaced with positive emotions of pleasure and joy at this new discovery. Later as they became used to the routine and various challenges set by the learning environment and the disappointments that arose out of not always being able to succeed in resolving problems negative emotions revealed themselves. Throughout the practical from the second week onwards students periodically revealed emotions related to their own awareness of their growing confidence and self esteem within the situation. This is illustrated in the following narrative boxes providing extracts from the reflective journals of three of the students.

\section{Student E}

1st week:

... initially I was a bit overwhelmed at the multiple disabilities that some individuals have among all their social problems ... where do we start with these individuals? ... I do feel a little anxious about the community especially as I am going to be working with the toddlers and due to my decreased self esteem I feel I need to learn a lot....

2nd week:

I feel less worried about the Valley than I was initially

3rd week:

I feel more confident now because we seem to be moving in some direction. 4th week:

Gth week:

I thoroughly enjoyed the home visits today.

The only thing that irritated me today was that the community members did not bring their garden tools today...... we shouldn't get annoyed but it almost seems like the group is not motivated to start the garden. 


\section{Student A}

2nd Week:

We as students are really looking forward to learn some of these skills and meeting the rest of the children....

3rd Week:

I had a wonderful time today I enjoyed every moment of it.

5th Week:

I was chairing the meeting ....I really enjoyed it..... I think I managed very well 6th Week: and give myself credit for that.

The beadwork group also has started although it is going slow due to them forgetting needles....

\section{Student I}

1st week:

Our experience at Ngcolosi didn't seem to be as exciting as was reported by other groups ....there seemed to be a general atmosphere of helplessness amongst the 3rd week: people there, which was slightly disappointing to observe.

9th week:

Overall a lovely and well structured day!

We had a planned and organized morning for today and were all well prepared brilliant pre-planning.

10th week:

Following visit to foster home of one of the children:

This was honestly something that did not have a good impact on me. The new conditions that this little boy has to live in was below that what he was used to.

\section{Theme 2: New Learning experiences and challenges}

Both early on in the experience and as the students progressed within the practical exposure time they reflected continuously and with some excitement on their new learning experiences. These especially included their ability to apply basic theoretical principles in the practical situation and the benefits of transprofessional interaction. It also included their growing ability to cope with working in an underresourced environment amongst people whose language most could not speak and who were mostly living in quite extreme poverty. 


\section{Student F}

3rd Week:

Later I got to see Philile's Mom feed her. It was amazing to see this done properly.

It must take LOTS of practice."

\section{Student G}

10th Week:

We learned that we should practice to look to the people(sic) as a whole and work towards helping them rather than for our own benefits.

\section{Student K}

6th Week:

I learned a lot from that experience, especially on how you could assess through observing and combining activities to get different results for the different health professionals".

\section{Student B}

Final week

The biggest challenge for me, was the language barrier and working with interpreters. I feel that working/communicating via an interpreter sometimes loses the essence of what is being said and things are not always directly translated.

Theme 3: Evolution of strategies to deal with emerging needs - Problem solving:

A definite emergence of awareness of, and skills in, applying strategies that could be used to overcome problems that had initially seemed insurmountable is evident in most student's reflections. This went closely together with the student's own growing confidence and self esteem in the situation.

\section{Student D}

12th session 12

Discussing problems related to birds eating the seedlings in the vegetable garden: During the first part of the morning we decided to make a scarecrow. Having no materials with us, we looked around to find some scrap paper bags, wood and wire. From this I learnt the importance of group work in that one can share different ideas and/or plans in order to fulfill a goal.

\section{Student B}

Last session:

When working in a community I've come to realize that things don't always go according to plan. Therefore, one needs to be well prepared for anything and be flexible enough to make adjustments, where necessary. 
Theme 4: Awareness of their role in making a difference

As the students progressed and gained both skills and confidence in working in this particular community they also expressed their awareness of where and how they had observed the positive outcomes of their various interventions. This was clearly a situation in which they were able to observe their theory being put into practice and that it actually worked. This was mostly evident from the middle of the practical exposure period until the end of it.

\section{Student C}

Final week

The most rewarding aspect ....... to be able to see the joy of the family as a child crawls for the first time or lifts his head. When we taught 'Thombifuthi some sign

\section{Student J}

language and we communicated. These moments were priceless.

17th week

Since the beginning of this year, where we started with a group since initial stage I'm proud of....

\section{Student L}

14th week

Although I've always known the importance of gross motor activities before actual where there was reluctant (sic) to participate we overcome this obstacle, now our group are in cohesion which activity participation, I found that the morning exercises gives them ( the children in the group)a lot of motivation and energy.

\section{How reflections reveal the achievement of learning outcomes}

The reflective journals mostly revealed evidence of students achievement of outcomes related to application of their professional theoretical and clinical skills and knowledge.

The following are a few examples of how this was revealed:

1. Demonstrate sensitivity to diversity and appropriate attitude and ability to work in different community and cultural settings: Most of the students indicated their awareness of and respect for the diversity of cultural experiences they were exposed to i.e. not only in terms of the particular community which was almost exclusively of the Zulu culture and language group, but also a respect for each other as a diverse group of students from African, European and Indian cultures.

\section{Student E}

... just to watch people really show off their culture (referring to dancing and 
singing) It was amazing to see children, some with severe disabilities, become so involved and move to the rhythm of the music. It really brought home the fact that one should never be judgemental of ones disability because people can really surprise you with their potential"

\section{And later:}

It was a humbling experience. I've learnt to appreciate life so much more because there are people out there that have much bigger problems to deal with yet they can still smile and make the best of life.

2. Able to plan and implement appropriate interventions and recommendations for different settings.

Students demonstrated an ability to quickly adapt to the situation and use whatever resources were available at the time. The example of making a scarecrow is one and the following shows the ability to explore solutions to very difficult situations:

\section{Student C}

After expressing her concern and sense of helplessness after a mother confessed the husband's physical abuse of her and sexual abuse of her 16 year old daughter.

We (the students) were thinking of maybe discussing (the formation of) a support group for abused women, but is this culturally appropriate to a community in(sic) which women are expected to be subservient and may be chastised?...."

\section{Student I}

Working with the translator actually went so well and skills were shared both ways. I learned Zulu while she was made aware of the type of questions to ask when assessing a child's receptive language level of understanding.

3. Demonstrate an ability to deal with community structures and show appropriate attitude, process and procedure for community entry and negotiation.

Initially students demonstrated some apprehensiveness in their ability to deal with community structures however this improved with time.

\section{Student F}

3rd week

I chaired the meeting today. I really was embarrassed which doesn't happen often!

We are still getting to know these people and I'm sure take time before we are $100 \%$ confident chairing a meeting. 


\section{Student C}

Discussing a visit to one of her children's homes:

... wow what a success. We got the mum and gran to practice as we went along. We

used the resources they had at home to form bolsters and wedges etc.....we were all

given refreshments and thanked many times I feel humbled by their generosity.

4. Demonstrate a thorough understanding of the needs of care providers, effectively consult and transfer of skills to both family members and employers.

This was one outcome that really was repeatedly demonstrated by students.

\section{Student C}

Discussing the same home visit as above:

We had a feeding session and we demonstrated the optimal feeding positions. A

(Speech Therapy student) will help the mum make an adapted cup for when the child is older. I will organise a CP chair as soon as the child will be too big to feed on the mother's lap.

\section{How reflections reveal the achievement of learning outcomes}

This research has revealed that the use of reflective journals in service learning situations not only fulfils the role of allowing students to think about and attach meaning to their experiences (Bringle \& Hatcher, 2005), and as Hutchings (2006) suggests, providing for increased self awareness and reflective skills, they also provide a very useful yardstick for assessing learning in a manner which is non-threatening and interesting for the student. It was evident from the student's entries that they were able to interpret observations made, reflect on their practice and adapt their responses to certain situations through journaling. This is supported by this statement by Shardlow \& Doel, as cited in Smith \& Jack (2005) "the record and analysis of experiences enable the students and mentor to explore the nuances of practice, their own perceptions and interpretations of these experiences, and, ultimately the appropriate professional response.

The final comments from the students also revealed how a Service Learning situation was probably to them one of the most influential in changing attitudes and causing positive learning experiences for the students. This is supported by Pavlovich (2007) who stated that the final dimension in reflection is that of realizing the influence of learning in a context, in changes in behaviour in the future.

\section{Student I}

The skills that I have learned have made my outlook on this clinic a positive one.

(in comparison to my attitude when I was first exposed to this clinic)... As I progressed throughout the year the most critical aspect of growth for me was my attitude change. 


\section{Student E}

I cannot believe that the time has gone so fast....... it was an enriching as well as a humbling experience.

\section{Student B}

I have truly learnt so many skills that have not only improved my clinical (speech therapy) knowledge and skills, but also my general life skills. Skills that I am sure will hold me in good stead for my community service experience next year.

\section{Student A}

If we had not done this course I personally think we would not have been well prepared for the community service type of work next year....

\section{Student H}

Initially I was not keen on skills sharing, I felt it was a breach of ethics.....but at the end of the year I can say I really read into the term 'skills sharing'.

The students' development and their ability to meet the outcomes of the module were also evident in their reflection. This will aid facilitators in identifying learning needs which may not be accounted for in the module outcomes as the students progressed through their community experiences. According to Smith $\&$ Jack (2005), reflective journaling can aid in detection of learning needs.

An unexpected revelation for the researchers in analysing these journals was that they also revealed shortcomings in their own expectations of the students. For example reflections throughout tended to be mostly on a fairly superficial level and thus as Hubbs \& Brand (2005) caution, this impacted on their ability to reach higher levels of reflection which could have been facilitated by their lecturers.

\section{Bibliography}

Braveman, B., \& Bass-Haugen, J.D. 2008. Social Justice \& Health Disparaties: An Evolving Discourse in Occupational Therapy Research and Intervention. American Journal of Occupational Therapy, 63(1) 7-12.

Bringle, R., \& Hatcher, J. 2005. Service learning as scholarship: Why theory-based research is critical to service learning. Acta Academia supplementum, 3: 24-44.

Duncan, M., \& Aulsop, A. 2006 Practice and Service Learning in Context. In L. M. Duncan., H. Buchanan. \& A. Alsop (Eds.), Practice and Service Learning in Occupational Therapy: Enhancing Potential in Context (p.7-19). Chichester.John Wiley \& Sons, Ltd. 
Duncan, M., \& Watson, R. 2004. Transforming through occupation: towards a prototype. In R. Watson., \& L. Swartz. Transformation through Occupation (p.301-318). London, Whurr Publishers.

Harris, M. 2005. Is journaling empowering? Students' perceptions of their reflective writing experience. Health SA Gesondheid, 10(2): 47-60.

Hubbs, D.L., \& Brand, C.F. 2005. The paper mirror: Understanding reflective journaling. The Journal of Experiential Education. 20(2):60-71.

Hutchings, C. 2006. Tracking identities in transition using reflective literacy. South African Journal of Higher Education, 20 (2): 232-244.

Johnson, D.W., Johnson, R.T., and Smith, C.T., 1991. Coorperative Learning: Increasing College Faculty Instructional Productivity. ASHE-ERIC Higher Education Report No.4, 1991. School of Education \& Human Development. George Washingtom University. Washington,DC.

Julie, H., Daniels, P. and Adonis, T. 2005. Service learning in nursing. Integrating student learning and community based service experience through reflective practice. Health SA Gesondheid, 10(4): 41-54.

Mitchell, C., \& Humphries, H. 2007. From notions of charity to social justice in service learning: The complex experience of communities. Education as Change 11(3): 47-58.

Nygaard, C., Hojlt, T., \& Hermansen, M. 2008. Learning-based curriculum development. Higher education, 55: 33-50.

Pavlovich, K. 2007, The development of reflective practice through student journals. Higher Education Research \& Development, 26 (3): 281 -295.

Shaw, S., \& Jolley, C.S. 2007. Assessment of service learning in the Deaf-Blind community. The Journal of Experiential Education, 30(2): 134-152.

Smith, A., \& Jack, K. 2005. Reflective practice: a meaningful task for students. Nursing Standard. 19(26): 33-37. 